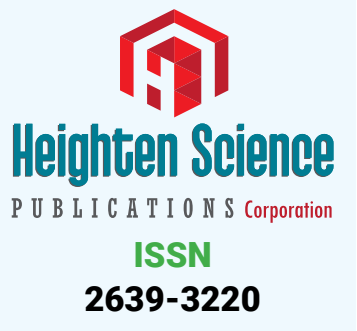

*Address for Correspondence: PEROU

Sébastien, Department of Vascular and Thoracic Surgery, Grenoble University Hospital, Boulevard de la Chantourne 38700 La Tronche, France. Tel: 0033476767575; E-mail: sperou@chugrenoble.fr

Submitted: 20 October 2016

Approved: 02 January 2017

Published: 03 January 2017

Copyright: @ 2017 Sébastien et al. This is an open access article distributed under the Creative Commons Attribution License, which permits unrestricted use, distribution, and reproduction in any medium, provided the original work is properly cited.

Keywords: Carotid Stenosis; Early surgery; Results; Brain infarct

\title{
Analysis of early Versus Delayed Carotid Surgery after Acute Ischemic Stroke
}

\author{
PEROU Sébastien ${ }^{1 *}$, DETANTE Olivier ${ }^{1}$, SPEAR Rafaelle ${ }^{3}$, \\ PIRVU Augustin ${ }^{1}$, ELIE Amandine ${ }^{2}$, MAGNE Jean-Luc ${ }^{1}$ \\ 'Departments of Vascular and Thoracic Surgery, Grenoble University Hospital, France \\ ${ }^{2}$ Neurology and Stroke Center, Grenoble University Hospital, France \\ ${ }^{3}$ Vascular Surgery Lille University Hospital, France
}

\section{ABSTRACT}

Objective: We evaluated the 30 -day outcomes of early ( $\leq 14$ days) or delayed (15 days to three months) carotid revascularization (CR) performed in patients who presented acute brain infarction secondary to internal carotid artery (ICA) stenosis.

Methods: We included all patients with a recent cerebral infarction from July 2010 to June 2014 who underwent $C R$ in our center within three months after the onset of symptoms for ICA stenosis. Data were retrospectively collected. Two groups were identified: Group $A$ included patients who underwent early $C R$ within the first fourteen days after symptom onset, and Group B, patients who underwent delayed $C R$, from the fifteenth day up to the third month after symptom onset. Death, stroke and major adverse cardiac events (MACE) were analyzed.

Results: Seventy-one patients underwent CR (73.2\% men, with a median age of 71). Nineteen patients underwent early $C R$ and 52 underwent delayed $C R$. The mean interval from initial examination to surgery was 9.5 days (range, 3-14 days) in Group A and 42 days (range, 15-92 days) in Group B. No complication occurred in Group A within the 30 postoperative days. In Group B, no MACE or death was observed and two patients presented with post-operative stroke (3.8\%).

Conclusion: This retrospective study confirmed the satisfactory outcomes of early CR after acute brain infarct. Accurate clinical and radiological selection of patients prevents early neurological complications.

\section{INTRODUCTION}

Development of stroke units and increased accessibility to high-performance brain imaging has improved the early care of patients presenting with acute neurologic focal deficit. When significant carotid stenosis is responsible for neurological symptoms, surgical care is recommended [1-3]. Nevertheless, delay between surgery and symptom onset remains a key question. Indeed, early carotid revascularization decreases the risk of stroke recurrence, but can also result in new cerebral infarction or hemorrhagic transformation of the preexisting ischemic lesion. Many randomized trials have shown the benefit of early carotid revascularization for symptomatic carotid stenosis in stable patients [4]. According to recent literature, carotid revascularization (CR) should be performed within the first two weeks following transient ischemic attack (TIA) or minor stroke, [5-8] and to some extend in the hyperacute period, within 48 hours $[9,10]$. In contrast, regarding major strokes or ongoing strokes, major studies recommend that surgery should be delayed four to six weeks after the first neurological symptoms when clinical and radiological lesions have stabilized [11,12]. However, some recent series with excellent outcomes after early revascularization during the acute phase of 
major stroke have questioned revascularization delay [13-15]. The main objective of our study was to evaluate the 30-day outcomes of early or delayed CR performed in our department in patients who presented acute brain infarction secondary to internal carotid artery (ICA) stenosis.

\section{METHODS}

\section{Study design}

A retrospective single-center study was conducted in Grenoble University Hospital on the outcomes of CR after acute ischemic stroke. We collected data on all patients who had undergone CR from July 2010 to June 2014 from the vascular surgery database. Patients with asymptomatic carotid stenosis and patients requiring combined CR and cardiac bypass were excluded. Data from patients with symptomatic carotid stenosis were combined with the stroke unit database. All patients had brain images and patients who presented with TIA were excluded. Thus, all consecutive patients who underwent CR in our department within three months after the stroke were included. Data collected included demographics, medication, neurological presentation. Neurologic presentation included: symptom onset, neurological deficit and NIHSS (National Institute of Health Stroke Score: neurological gravity score after stroke) on admission. Evolution of neurologic symptoms were also evaluated. Radiological data (carotid duplex ultrasound imaging and brain imaging), preoperative workup, operative details, complications, clinical and ultrasound imaging on follow-up at one month and three months. Primary outcomes were 30-day postoperative mortality, stroke, and MACE.

\section{Definitions}

An internal carotid artery (ICA) stenosis was defined as symptomatic when it was responsible for a focal neurological deficit of the corresponding cerebral territory. We defined a single transient ischemic attack (TIA) as a focal neurological deficit lasting less than one hour without any recent ipsilateral lesion on brain imaging. We defined a stroke as a focal neurological deficit associated with a radiological lesion of the corresponding brain territory. We used the term "brain infarct" rather than "stroke" to describe radiological lesions in order to differentiate ischemic lesions from hemorrhagic lesions. The cohort was divided in two groups. Group A included all patients who underwent CR within the first 14 days after symptom onset. Group B gathered patients who underwent CR from day fifteen to three months after the initial examination.

\section{Emergency diagnostic workup}

Patients received standardized preoperative care. On admission, a neurological evaluation was immediately performed by a neurologist who described symptoms, severity and duration. The NIHSS was always evaluated. NIHSS was secondarily evaluated once patients were referred to our university hospital based on the initial complete neurological description. Brain imaging (CT scan or MRI) was systematic to confirm diagnosis and to rule out hemorrhagic infarction. Patients were hospitalized in the stroke unit and received optimal medical therapy with antiplatelet agents and statins. Eligible patients received thrombolytic therapy. Duplex ultrasound imaging combined with CT or MR angiography were used for the diagnosis of ICA stenosis > 60\% according to the North American Symptomatic Carotid Endarterectomy Trial (NASCET) criteria [11]. Once diagnosed, the patient was referred to the vascular surgery ward to be operated on if he showed clinical improvement and no hemorrhage or massive infarct (defined as infarct $>3 \mathrm{~cm}$ or with brain edema) on brain imaging. A second brain CT-scan was performed one month later in the presence of hemorrhagic lesion. Patients previously treated by thrombolysis were contraindicated for early 
surgery. Patients initially admitted in small regional hospitals were first transferred in neurology before surgical management.

\section{Operative procedure and outcomes}

Surgery was always performed under general anesthesia with a standardized surgical technique. Blood pressure was monitored by invasive blood pressure measurement. Heparin $(50 \mathrm{IU} / \mathrm{kg}$ ) was administered intravenously before clamping. Shunt was used when residual pressure was $<50 \mathrm{mmHg}$ or when backflow from the ICA was observed pulseless. Endarterectomy with patch angioplasty was used when a shunt was necessary. In other cases, eversion carotid endarterectomy or bypass was performed at surgeon's discretion. Carotid duplex ultrasound imaging was systematically performed by the surgeon at the end of the CR. Systolic blood pressure (SBP) was monitored every 15 minutes in the recovery room and SBP was only treated when $>160 \mathrm{mmHg}$. During postoperative hospitalization in the vascular surgery department neurological evaluation was repeated regularly. A new persistent neurological deficit with concordant brain imaging was classified as a new stroke. A major cardiac event was defined as ischemic electrocardiographic modifications and elevated troponin. Follow-up neurological examinations were performed by the vascular surgeon at one and three months and by the neurologist at six months. After discharge, all patients were scheduled for carotid duplex ultrasound imaging at three months.

\section{Statistical analysis}

Results were expressed as means with standard deviations or as median with interquartile range (IQR) when appropriate. Statistical analysis was performed using the Wilcoxon-Mann-Whitney test, $\mathrm{Chi}^{2}$ test or, when appropriate, the Fisher exact test. Significance was assumed at $p<0.05$.

\section{RESULTS}

From July 2010 to June 2014, 447 patients (154 symptomatic patients $(34.4 \%)$ and 293 asymptomatic patients) were treated for carotid stenosis. Among symptomatic patients, TIA was diagnosed in 61 patients (39.6\%) and stroke in 93 patients $(61.4 \%)$. Among these 93 patients, 22 patients were excluded because symptoms appeared more than three months prior to CR. Overall, 71 consecutive patients who underwent CR after an acute ischemic stroke were included in our study. Nineteen patients underwent surgery within the first fourteen days (Group A) and 52 patients were treated between day fifteen and three months (Group B).

\section{Patient characteristics}

Population included was 52 men (73.2\%) and 19 women (26.8\%), with a median age at presentation of 71 years (IQR, 65-78 years). The two groups did not significantly differ in age and sex (Table 1). Prevalence of cardiovascular risk factors such as smoking, diabetes, obesity or hypercholesterolemia was similar in both groups. Group B showed a significantly higher rate of patients with systemic hypertension $(80.8 \% \mathrm{vs}$. 57.9\%; $p=0.05$ ). Demographic characteristics are presented in table 1 .

\section{Peri-operative management}

On admission, median NIHSS was significantly higher in Group B than in Group A ( 5 [range, $0-27$ ] vs. 3 [range, $0-7$ ] respectively; $p=0.04$ ). Three patients had NIHSS $>15$ with a major neurological deficit. All patients underwent brain imaging: 56 had MRI and 15 had CT scans. All patients had one or more recent ischemic infarcts $<3 \mathrm{~cm}$ in the involved hemisphere. MRI was more frequent in Group A (89.5\% vs. 75\%; $p=0.32$ ) but the difference was not significant. Figure 1 illustrates imaging evaluation in a 87-yearold man with a left hemiplegia (NIHSS 6 at admission) who underwent surgery 30 days 
Table 1: Baseline characteristics and medical history.

\begin{tabular}{|c|c|c|c|c|}
\hline Variables $^{a}$ & Total $n=71$ & $\begin{array}{c}\text { Group A } \\
n=19\end{array}$ & $\begin{array}{c}\text { Group B } \\
n=52\end{array}$ & $P$ \\
\hline Age, years & $71[65 ; 78]$ & $69[65 ; 79]$ & $71.5[65.5 ; 78]$ & 0.90 \\
\hline Men & $52(73.2)$ & $16(84.2)$ & $36(69.2)$ & 0.21 \\
\hline Smokers (current/former) & $47(66.2)$ & $15(78.9)$ & $32(61.5)$ & 0.17 \\
\hline Hypertension & $53(74.6)$ & $11(57.9)$ & $42(80.8)$ & 0.05 \\
\hline Hypercholesterolemia & $39(54.9)$ & $10(52.6)$ & $29(55.8)$ & 0.81 \\
\hline Diabetes & $22(31)$ & $4(21.1)$ & $18(34.6)$ & 0.27 \\
\hline Obesity (BMI > 30) & $9(12.7)$ & $2(10.5)$ & $7(13.5)$ & 0.74 \\
\hline Chronic lung disease & $14(19.7)$ & $3(15.8)$ & $11(21.2)$ & 0.61 \\
\hline Renal impairment (clearance $<60 \mu \mathrm{mol} / \mathrm{l}$ ) & $6(8.5)$ & $1(5.3)$ & $5(9.6)$ & 0.56 \\
\hline Atrial fibillation / valvular heart disease & $6(8.5)$ & $2(10.5)$ & $4(7.7)$ & 0.70 \\
\hline Coronary artery disease & $18(25.4)$ & $7(36.8)$ & $11(21.2)$ & 0.18 \\
\hline Previous stroke or TIA & $14(19.7)$ & $5(26.3)$ & $9(17.3)$ & 0.40 \\
\hline American Society of anesthesiologists & & & & 0.59 \\
\hline Grade I & $1(1.4)$ & 0 & $1(1.9)$ & - \\
\hline Grade II & $19(26.8)$ & $7(36.8)$ & $12(23.1)$ & - \\
\hline Grade III & $50(70.4)$ & $12(63.2)$ & $38(73.1)$ & - \\
\hline Grade IV & $1(1.4)$ & 0 & $1(1.9)$ & - \\
\hline NIHSS & $3[0 ; 21]$ & $3[0 ; 7]$ & $5[0 ; 27]$ & 0.04 \\
\hline Thrombolytic therapy & $10(14.1)$ & 0 & $10(19.2)$ & 0.04 \\
\hline $\begin{array}{l}\text { Optimal medical therapy } \\
\text { (antiplatelet + statin) }\end{array}$ & $26(36.6)$ & $8(42.1)$ & $18(34.6)$ & 0.56 \\
\hline
\end{tabular}

BMI, Body Mass Index; TIA, transient ischemic attack

${ }^{a}$ Categoric data are shown as number (\%) and continuous data as median [Q1; Q3]

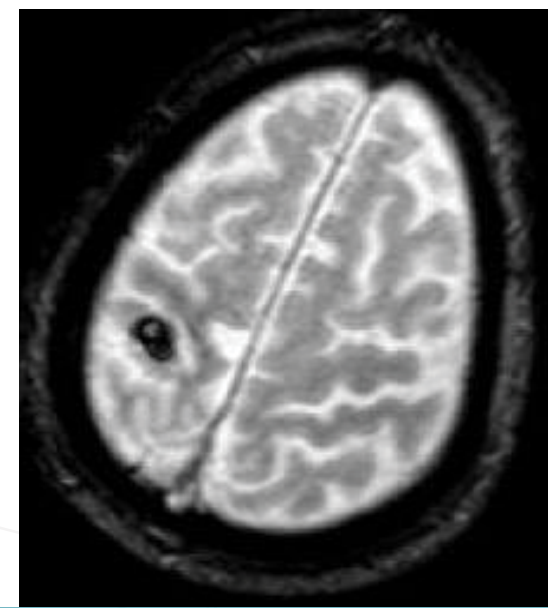

Figure 1: Preoperative MRI (T2*-weighted sequence) showing a recent hemorrhagic conversion $(8 \mathrm{~mm})$ of a superficial right territory brain infarction.

after onset of symptoms, after a control brain MRI because of a hemorrhagic lesion in this first image.

The topographic pattern of the cerebral ischemic lesion was analyzed for each patient. Sixteen watershed strokes were noted with a similar distribution between both groups. Among these 16 patients, we found combined border-zone and territorial (in the middle cerebral artery (MCA) territory) stroke caused by multiple emboli in nine patients. Systematic carotid duplex ultrasound imaging associated with CT angiography (or MRI in case of severe renal impairment) was performed to evaluate the internal carotid stenosis. Results are listed in table 2 . Figure 2 illustrates a right 
Table 2: Brain imaging and results of carotid duplex ultrasound imaging.

\begin{tabular}{|c|c|c|c|c|}
\hline Variables $^{a}$ & $\begin{array}{l}\text { Total } \\
n=71\end{array}$ & $\begin{array}{c}\text { Group A } \\
n=19\end{array}$ & $\begin{array}{c}\text { Group B } \\
n=52\end{array}$ & $p$ \\
\hline \multicolumn{5}{|l|}{ Brain imaging } \\
\hline CT scan & $15(21.1)$ & $2(10.5)$ & $13(25)$ & 0.32 \\
\hline MRI & $56(78.9)$ & $17(89.5)$ & $39(75)$ & 0.32 \\
\hline \multicolumn{5}{|l|}{ Type of infarct } \\
\hline Watershed strokes & $16(22.5)$ & $6(31.6)$ & $10(19.2)$ & 0.34 \\
\hline Territorial strokes & $55(77.5)$ & $13(68.4)$ & $42(80.8)$ & 0.34 \\
\hline Combined strokes (watershed and territorial) & $9(12.7)$ & $4(21.1)$ & $5(9.6)$ & 0.24 \\
\hline \multicolumn{5}{|l|}{ Carotid duplex ultrasound imaging } \\
\hline Significant ICA stenosis $>60 \%^{\mathrm{b}}$ & $65(91.5)$ & $18(94.7)$ & $47(90.4)$ & 0.99 \\
\hline Residual ICA stenosis post-thrombolysis & $1(1.4)$ & 0 & $1(1.9)$ & 0.99 \\
\hline Stenosis on single ICA & $2(2.8)$ & 0 & $2(3.8)$ & 0.99 \\
\hline Nearly occlusive ICA stenosis & $5(7)$ & $1(5.3)$ & $4(7.7)$ & 0.99 \\
\hline Contralateral stenosis on single ICA & $1(1.4)$ & 0 & $1(1.9)$ & 0.99 \\
\hline ICA stenosis $50 \%$ (ulcerated plaque) ${ }^{b}$ & $5(7)$ & $1(5.3)$ & $4(7.7)$ & 0.99 \\
\hline Grade of ICA stenosis (\%) & $75[70 ; 80]$ & $80[70 ; 85]$ & $72.5[70 ; 80]$ & 0.08 \\
\hline
\end{tabular}

ICA, Internal Carotid Artery

${ }^{\mathrm{a}}$ Categoric data are shown as number (\%) and continuous data as median [Q1; Q3]. ${ }^{\mathrm{b}} \mathrm{According}$ to the NASCET criteria

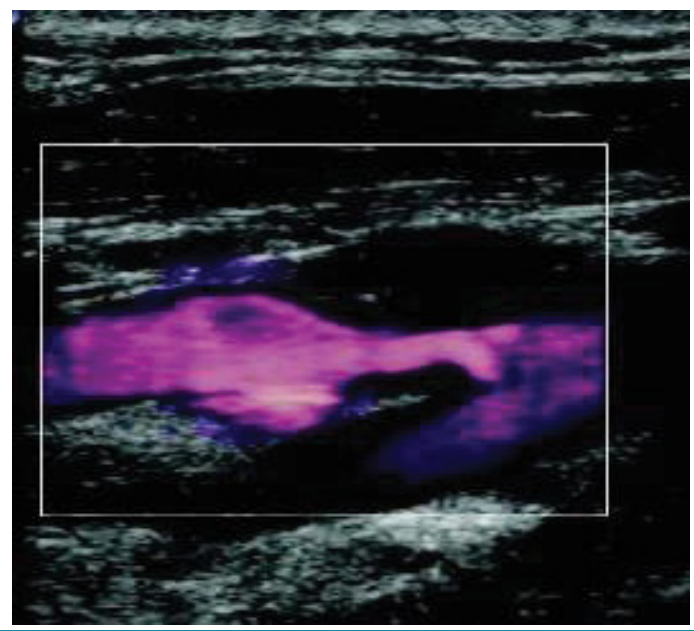

Figure 2: Preoperative carotid duplex ultrasound showing a 70\% (NASCET) right ICA stenosis.

ICA stenosis on carotid duplex ultrasound imaging. All patients received medical therapy (antiplatelet and statin) before surgery. Ten eligible patients (14.1\%) received thrombolytic therapy, all belonging to Group B ( $0 \%$ vs. $19.2 \% ; p=0.04)$.

\section{Surgery}

The mean interval from initial examination before surgery was 9.5 days (range, 3-14 days) in Group A and 42 days (range, 15-92 days) in Group B. Among seventeen patients initially treated in small regional hospitals, 14 belonged to Group B. Based on residual pressure measurement and an evaluation of the backflow in the ICA, five patients in Group A and seven patients in Group B required the use of shunt. No significant difference was observed $(26.4 \%$ vs. $13.5 \% ; p=0.20)$. Surgery performed were similar in both groups. Intraoperative results are summarized in table 3.

\section{Outcomes and follow-up}

At one month, no death, no recurrent stroke or TIA and no cardiac complication was observed in Group A with a 100\% complete follow-up. In Group B, among the $98.1 \%$ 
Table 3: Operative details and outcomes.

\begin{tabular}{|c|c|c|c|}
\hline Variables $^{a}$ & $\begin{array}{c}\text { Group A } \\
n=19\end{array}$ & $\begin{array}{c}\text { Group B } \\
n=52\end{array}$ & $p$ \\
\hline \multicolumn{4}{|l|}{ Surgery } \\
\hline Timing (onset - surgery), days & $9.5[3-14]$ & $42[15-92]$ & - \\
\hline General anesthesia & $19(100)$ & $52(100)$ & - \\
\hline \multicolumn{4}{|l|}{ Type of surgery } \\
\hline Endarterectomy and direct closure & $1(5.3)$ & $2(3.8)$ & 0.79 \\
\hline Eversion endarterectomy & $6(31.6)$ & $14(26.9)$ & 0.70 \\
\hline Endarterectomy + patch angioplasty & $6(31.6)$ & $9(17.3)$ & 0.19 \\
\hline Bypass venous grafting & $5(26.3)$ & $25(48.1)$ & 0.10 \\
\hline Bypass prosthetic grafting ${ }^{b}$ & $1(5.3)$ & $2(3.8)$ & 0.79 \\
\hline Shunting & $5(26.3)$ & $7(13.5)$ & 0.20 \\
\hline Duration of surgery, min & $110[75-180]$ & 120 [64-168] & 0.02 \\
\hline Postoperative SBP, $>160 \mathrm{mmHg}$ & $15(78)$ & $43(82.7)$ & 0.40 \\
\hline \multicolumn{4}{|l|}{ 30-day clinical outcomes } \\
\hline Stroke & 0 & $2(3.8)$ & 0.39 \\
\hline Death & 0 & 0 & - \\
\hline Major adverse cardiac event & 0 & 0 & - \\
\hline \multicolumn{4}{|l|}{ 90-day duplex ultrasound imaging outcomes } \\
\hline Normal exam & $17(100)$ & $48(96)$ & 0.40 \\
\hline Carotid stenosis & 0 & $2(4)$ & 0.40 \\
\hline Lost to follow-up & $2(10.5)$ & $2(3.8)$ & - \\
\hline
\end{tabular}

SBP, Systolic Blood Pressure

aCategoric data are shown as number (\%) and continuous data as mean [range].

bPolytetrafluroethylene was used

follow-up (one patient was lost on follow-up), two patients had a postoperative stroke (Table 3). The overall combined morbidity/mortality rate was $2.8 \%$. The combined morbidity/mortality rate for the Group B was 3.8\%. At three months, among the $96.4 \%$ follow-up, all patients had favorable functional outcome. Follow-up carotid duplex imaging performed at three months depicted two stenoses in patients who underwent venous bypass. Stenosis was observed on distal anastomosis and measured $50 \%$. No symptom was observed and patients benefited of regular duplex imaging follow-up.

The two neurological outcomes observed were acute postoperative strokes in the first 48 hours after surgery. The first occurred in an 80-year-old man (American Society of anesthesiologists (ASA) III) who initially presented with left hemiplegia and with a NIHSS of 10. Initial brain imaging showed a right superficial territorial stroke. The patient underwent thrombolysis. Surgery was performed 56 days after symptom onset and consisted of carotid endarterectomy with patch angioplasty without shunt. This patient developed on early postoperative period a high SBP (> 200 $\mathrm{mmHg}$ ) and a new stroke in the recovery room. CT scan depicted a hematoma in the deep right MCA territory. The second patient was a 65-year-old man (ASA III) who was admitted with left hemiplegia and NIHSS of seven. Initial brain imaging showed the deep right territorial stroke. A 70\% ICA stenosis was operated 28 days after symptom onset with bypass venous grafting. Postoperative follow-up was complicated with hypertension and a new stroke one day after surgery. A new lesion with a right occipital hematoma was found on CT scan.

Among the 12 patients who required the use of a carotid shunt, 33.3\% had a former history of stroke or TIA (vs. $15.3 \%$ in the rest of the cohort). Their median grade of ICA stenosis was more severe (80\% [IQR, 72.5\%-90\%] vs. 75\% [IQR, 70\%-80\%]; $p$ $=0.01)$ and occlusive ICA stenoses $>95 \%$ were more frequently treated $(25 \%$ vs. 
$3.4 \% ; p=0.003)$. More watershed strokes were found in these patients $(58.3 \% \mathrm{vs}$. $15.3 \% ; p=0.004$ ). None of these patients received thrombolysis and no postoperative complication occurred.

Among the ten patients who received thrombolysis, all had systemic hypertension. On admission, their neurological status was more severe. The mean NIHSS was 12 ((range, 2-27), $p<0.0001$ ). All patients were ASA III (100\% vs. $65.6 \% ; p=0.03$ ). No patient underwent early surgery and the mean interval from initial examination before surgery was 46 days (range, 16-92 days).

\section{DISCUSSION}

This study confirms favourable outcomes results after early CR for acute ischemic stroke. Performing CR in an urgent setting after a neurological deficit requires close collaboration between vascular surgeons and neurologists that is nowadays possible thanks to stroke units. In preoperative management, the timing of surgery is one of the most important issues.

For patients who require CR after brain infarct, the key question is the evaluation of both benefits and risks of early surgery. The aim of early surgery is to restore blood flow to the ischemic penumbra to improve neurological symptoms and to reduce the risk of carotid occlusion and recurrent embolic stroke. The major risk of an ischemic lesion is the occurrence of hemorrhagic stroke. A recent literature review by Naylor et al. 2008; [16] on conversion rates from ischemic stroke to hemorrhagic stroke after early $\mathrm{CR}$, concluded that the rate of symptomatic intracranial hemorrhage was low from $0 \%$ to $2 \%$.

Delay before surgery for patients who suffered a TIA due to internal carotid stenosis is established and surgery should be performed precociously [5-8]. This is why we excluded all patients presenting with TIA, in order to focus on stroke outcomes. Results of emergent CR depend on the surgical team and the severity of the initial stroke. This surgery is considered to be at high risk. Nevertheless, several small monocentric studies reported favourable outcomes, including patients with major strokes during acute phase $[15,17,18]$. Lesèche et al. 2012; reported no death or postoperative stroke for 27 patients who underwent CR during the acute phase of stroke with a median delay of six days from symptom onset to surgery [13]. Results of these studies tend to consider a prompt surgical approach. The aim of our study was to analyze our 30-day outcomes after early CR compared to delayed CR, and to evaluate the quality of our selection criteria.

In our study, postoperative outcomes were favourable with an overall combined morbidity/mortality rate of $2.8 \%$. The absence of postoperative complication in Group A confirms the quality of selection criteria for early CR. These favourable outcomes can be explained by three reasons. First, there was a close cooperation between vascular surgeons, neurologists and neuroradiologists. Second, the diagnosis was fast with an easy access to brain imaging (80.3\% of patients had a brain MRI that allows a more accurate analysis compared to brain CT scan) and an optimal preoperative medical management. Lastly, surgery was performed by trained surgeons, using systematic residual pressure measurement and duplex ultrasound imaging by the operator at the end of surgery. In order to minimize perioperative risks, we implement low mobilization of the ICA and of the carotid bifurcation before clamping to prevent embolization, long arteriotomy, distal plaque fixation and closing the arteriotomy with a patch.

Selection criteria for early CR follow local guidelines, which are based on the experience of the surgical and neurological teams. Several conditions need to be met for early CR. The first condition is clinical improvement. Early CR is proposed only if patients present with neurological improvement during the workup. When NIHSS 
on admission is $>8$, we are usually more cautious and delay surgery. Early surgery is not performed if the patient suffers from a major disabling stroke. For patients with advanced age ( $>85$ years), the surgical indication depends on medical history, clinical condition and neurological improvement. Patients treated recently with thrombolytics are not eligible for early surgery because of the high risk of hemorrhage. When hemorrhagic transformation, major ischemic infarct of $3 \mathrm{~cm}$ or more, or brain edema are depicted on brain imaging, early CR is contraindicated. In such cases, we repeat brain imaging and regularly discuss the delay for surgery.

Our study has several strengths. First, data collection was accurate with more than 60 clinical, radiological, anesthetic and surgical management categories. Second, all patients had standardized preoperative and operative management, with followup clinical exams at 30 days and 90 days and duplex ultrasound imaging at 90 days. Only one patient was lost on follow-up in the 30-day postoperative period. Despite the small number of patients included resulting in a low power of statistical analysis, the exclusion of patients with TIA reduced the interpretation biases concerning the outcomes of early CR, which could have been increased by the usually excellent outcomes in these patients.

We acknowledge several limitations to our study. First, it was a retrospective study. However, data collection was thoroughly performed. NIHSS was missing for 17 patients. Detailed neurologic examination on admission allowed us to evaluate retrospectively NIHSS whether patients were secondarily transferred or primarily admitted in our facility. The retrospective evaluation limits the interpretative part of NIHSS. Second, Group A was rather small due to a delay in the management of patients presenting with strokes when patients were referred secondarily to the university hospital. Moreover, the surgical team preferred delaying the surgery four weeks, during the first two years of the study. Indeed, among the 17 patients who initially consulted in small regional hospitals, only three (23.6\%) had surgery in the first two weeks.

We compared our series with other series recently published in the literature (Table 4). Many authors do not differentiate TIA and stroke when considering the outcomes of early CR. Results are based on all symptomatic patients. The lack of differentiation between the initial neurological events makes the interpretation and comparability of results between series difficult. In contrast, other series take into account the severity of the initial event. Their results should be interpreted taking into account the postoperative risks related to the severity of the initial lesion. For example, for Barbetta et al. 2014; the 30-day outcomes of early CR in 90 patients were considered as satisfactory despite four deaths and six postoperative strokes. In their series, half of the complications occurred in 11 patients who presented with severe stroke in evolution [15].Nevertheless, in many series, results suggest that early CR after brain infarct is safe.

Our results are coherent with the literature. The absence of complications in Group A could be explained by the accurate selection of patients. However, Lesèche et al. 2012; reported excellent outcomes of early CR performed in the acute phase of stroke in evolution, [13] a population with a higher risk profile that was excluded from Group A in our study. This could also explain our good results for this group. Several selection criteria, mainly radiological criteria, are frequently proposed in the literature. However, establishing an operability scale is made difficult because of the subjectivity and the variability of the clinical recovery between patients after stroke. The decision and the time of surgery remain at the discretion and the expertise of the surgical team.

In our series, all patients who underwent thrombolysis were operated later with a mean delay of 46 days. Guidelines recommend delaying surgery as much as possible after thrombolysis to decrease the risk of hemorrhage. Yet, with the increasing number 
Table 4: Comparison of surgical series of early carotid revascularization after stroke.

\begin{tabular}{|l|c|c|c|c|c|c|c|} 
& \multicolumn{5}{c}{ Clinical presentation } & \multicolumn{3}{c|}{ Outcomes } \\
\hline First author & CR (n) & TIA (\%) & Stroke (\%) & $\begin{array}{c}\text { Median delay } \\
\text { [day] }\end{array}$ & Death (\%) & MI (\%) & Stroke \\
Barbetta (2014)
\end{tabular}

${ }^{a}$ Continuous data are shown as median [Q1; Q3]. MI, Myocardial infarction. Nd, No data

of stroke units, the question of a rapid revascularization of residual ICA stenosis after thrombolysis has emerged. Recent studies reported reassuring results but they were small population studies [25-28].Among the two neurological complications in our study, one was a postoperative stroke after thrombolysis and delayed CR. We believe early CR after thrombolysis should be considered, but larger series of patients are required to confirm the safety of such management. A recent series also described more frequent postoperative complications among patients who underwent early CR after a watershed infarct [29].These data contrast with ours because no complication was observed in such patients, but our population was smaller with only 16 patients, including six who were treated early.

In conclusion, in accordance with the literature, our results on a small retrospective monocentric study are in favour of early CR after acute ischemic stroke. An accurate radiological selection of patients is essential to prevent early neurological complications. The current trend is to perform early CR in the acute phase of stroke. Larger series of patients are required to confirm the safety of this management strategy among some risk groups such as patients with stroke in evolution, patients who have watershed infarction or have undergone thrombolysis.

\section{REFERENCES}

1. Randomised trial of endarterectomy for recently symptomatic carotid stenosis: final results of the MRC European Carotid Surgery Trial (ECST). Lancet. 1998; 351: 1379-1387. Ref.: https://goo.gl/vN01Lz

2. Barnett HJ, Taylor DW, Eliasziw M, Fox AJ, Ferguson GG, et al. Benefit of carotid endarterectomy in patients with symptomatic moderate or severe stenosis. New Engl J Med. 1998; 339: 1415-1425. Ref.: https://goo.gl/gsNtSk

3. Mayberg MR, Wilson SE, Yatsu F, Weiss DG, Messina L, et al. Carotid endarterectomy and prevention of cerebral ischemia in symptomatic carotid stenosis. Veterans Affairs Cooperative Studies Program 309 Trialist Group. JAMA. 1991; 266: 3289-3294. Ref.: https://goo.gl//2Msvy2

4. Rothwell PM, Eliasziw M, Gutnikov SA, Fox AJ, Taylor DW, et al. Analysis of pooled data from the randomised controlled trials of endarterectomy for symptomatic carotid stenosis. Lancet. 2003; 361: 107-116. Ref.: https://goo.gl/waKQDv

5. Bond R, Rerkasem K, Rothwell PM. Systematic review of the risks of carotid endarterectomy in relation to the clinical indication for and timing of surgery. Stroke. 2003; 34: 2290-2301. Ref.: https://goo.gl/fKC9kg

6. Rothwell PM, Eliasziw M, Gutnikov SA, Warlow CP, Barnett HJ. Sex difference in the effect of time from symptoms to surgery on benefit from carotid endarterectomy for transient ischemic attack and nondisabling stroke. Stroke. 2004; 35: 2855-2861. Ref.: https://goo.gl/EPNGdy

7. Rothwell PM, Eliasziw M, Gutnikov SA, Warlow CP, Barnett HJ. Carotid endarterectomy trialists 
collaboration. Endarterectomy for symptomatic carotid stenosis in relation to clinical subgroups and timing of surgery. Lancet. 2004; 363: 915-24. Ref.: https://goo.gl/GGhelx

8. Ballotta E, Meneghetti G, Da Giau G, Manara R, Saladini M, et al. Carotid endarterectomy within 2 weeks of minor ischemic stroke: a prospective study. J Vasc Surg. 2008; 48: 595-600. Ref.: https://goo.gl/DwTHoq

9. Salem MK, Sayers RD, Bown MJ, Eveson DJ, Robinson TG, et al. Rapid access carotid endarterectomy can be performed in the hyperacute period without a significant increase in procedural risks. Eur $\mathrm{J}$ Vasc Endovasc. 2011; 41: 222-228. Ref.: https://goo.gl/S5nsBq

10.Department of Health. National Stroke Strategy. www.dh.gov.uk/stroke 2007. Accessed 2009.

11.North American Symptomatic Carotid Endarterectomy Trial Collaborators. Beneficial effect of carotid endarterectomy in symptomatic patients with high-grade carotid stenosis. N Engl J Med. 1991; 325: 445-453. Ref.: https://goo.gl/b10huk

12.MRC European Carotid Surgery Trial: interim results for symptomatic patients with severe (70 $99 \%$ ) or with mild (0-29\%) carotid stenosis. European Carotid Surgery Trialists' Collaborative Group. Lancet. 1991; 337: 1235-1243. Ref.: https://goo.gl/DFK4cj

13.Leseche G, Alsac JM, Houbbalah R, Castier Y, Fady F, et al. Carotid endarterectomy in the acute phase of stroke-in-evolution is safe and effective in selected patients. J Vasc Surg. 2012; 55: 701 707. Ref.: https://goo.gl/GveOIr

14.Capoccia L, Sbarigia E, Speziale F, Toni D, Biello A, et al. The need for emergency surgical treatment in carotid-related stroke in evolution and crescendo transient ischemic attack. J Vasc Surg. 2012; 55: 1611-1617. Ref.: https://goo.gl/u7K4NO

15.Barbetta I, Carmo M, Mercandalli G, Lattuada P, Mazzaccaro D, et al. Outcomes of urgent carotid endarterectomy for stable and unstable acute neurologic deficits. J Vasc Surg. 2014; 59: 440-446. Ref.: https://goo.gl/OzPfcQ

16. Naylor AR. Delay may reduce procedural risk, but at what price to the patient? Eur J Vasc Endovasc. 2008; 35: 383-391. Ref.: https://goo.gl/J4kEHa

17.Gertler JP, Blankensteijn JD, Brewster DC, Moncure AC, Cambria RP, et al. Carotid endarterectomy for unstable and compelling neurologic conditions: do results justify an aggressive approach? $\mathrm{J}$ Vasc Surg. 1994; 19: 32-40. Ref.: https://goo.gl/VJx0i6

18.Tsivgoulis G, Krogias C, Georgiadis GS, Mikulik R, Safouris A, et al. Safety of early endarterectomy in patients with symptomatic carotid artery stenosis: an international multicenter study. Eur J Neurol. 2014; 21: 1251-1257. Ref.: https://goo.gl/86e67v

19.Paty PS, Bernardini GL, Mehta M, Feustel PJ, Desai K, et al. Standardized protocols enable stroke recognition and early treatment of carotid stenosis. J Vasc Surg. 2014; 60: 85-91. Ref.: https://goo.gl/uj6FKh

20.Chisci E, Pigozzi C, Troisi N, Tramacere L, Zaccara G, et al. Thirty-day neurologic improvement associated with early versus delayed carotid endarterectomy in symptomatic patients. Ann Vasc Surg. 2015; 29: 435-442. Ref.: https://goo.gl/fald03

21.Faggioli G, Pini R, Mauro R, Gargiulo M, Freyrie A, et al. Perioperative outcome of carotid endarterectomy according to type and timing of neurologic symptoms and computed tomography findings. Ann Vasc Surg. 2013; 27: 874-882. Ref.: https://goo.gl/EK5yzd

22.Ferrero E, Ferri M, Viazzo A, Labate C, Berardi G, et al. A retrospective study on early carotid endarterectomy within 48 hours after transient ischemic attack and stroke in evolution. Ann Vasc Surg. 2014; 28: 227-238. Ref.: https://goo.gl/Tu6pFQ

23.Sbarigia E, Toni D, Speziale F, Acconcia MC, Fiorani P. Early carotid endarterectomy after ischemic stroke: the results of a prospective multicenter italian study. Eur J Vasc Endovasc. 2006; 32: 229235. Ref.: https://goo.gl/1694bm

24.Rockman CB, Maldonado TS, Jacobowitz GR, Cayne NS, Gagne PJ, et al. Early carotid endarterectomy in symptomatic patients is associated with poorer perioperative outcomes. J Vasc Surg. 2006; 44 480-487. Ref.: https://goo.gl/ntdorJ

25.McPherson CM, Woo D, Cohen PL, Pancioli AM, Kissela BM, et al. Early carotid endarterectomy for critical carotid artery stenosis after thrombolysis therapy in acute ischemic stroke in the middle cerebral artery. Stroke. 2001; 32: 2075-2080. Ref.: https://goo.gl/Omi4F2

26.Bartoli MA, Squarcioni C, Nicoli F, Magnan PE, Malikov S, et al. Early carotid endarterectomy after intravenous thrombolysis for acute ischaemic stroke. Eur J Vasc Endovasc. 2009; 37: 512-518. Ref.: https://goo.gl/XL4Jj8 
27. Crozier JEM, Reid J, Welch GH, Muir KW, Stuart WP. Early carotid endarterectomy following thrombolysis in the hyperacute treatment of stroke. Brit J Surg. 2011; 98: 235-238. Ref.: https://goo.gl/zlP6TI

28. Rathenborg LK, Venermo M, Troëng T, Jensen LP, Vikatmaa P, et al. Safety of carotid endarterectomy after intravenous thrombolysis for acute ischaemic stroke: a case-controlled multicentre registry study. Eur J Vasc Endovasc. 2014; 48: 620-625. Ref.: https://goo.gl/Y9MLj5

29.Jean-Baptiste E, Perini P, Suissa L, Lachaud S, Declemy S, et al. Prognostic value of preoperative border-zone (watershed) infarcts on the early postoperative outcomes of carotid endarterectomy after acute ischemic stroke. Eur J Vasc Endovasc. 2013; 45: 210-217. Ref.: https://goo.gl/3eXzH3 